\title{
Empowering Youth's Talks: A Classroom Reflection on the Utilizing Online Resources
}

\author{
Istiqomah Wulandari ${ }^{1}$, Yuni Astuti ${ }^{2}$ \\ \{istiqomah@ub.ac.id ${ }^{1}$, yuni_astuti@ub.ac.id ${ }^{2}$ \} \\ Universitas Brawijaya, Indonesia ${ }^{1,2}$
}

\begin{abstract}
Classes have been built to handle so-called digital resources in order to meet the demands of the twenty-first century. Using real-world tools, apps, and resources that are available online is inevitable for learning since today's generation has grown up with new networking devices such as a smartphone, smart device, and internet access. According to Prensky [1], this is a "digital native generation", which means that today's children were born into the e-environment and have access to worldwide information resources. Multimedia technology has transformed the face of second language pedagogy and added useful learning experience in the field of TESOL [2]. The use of multimedia resources has expanded learner engagement and optimized the teaching process [3]. The study's goals are intended to refer to the following areas: first, to analyze what kinds of online resources students use as tools to help with their presentation materials. Second, to explain how online resources can help students prepare and execute presentations for their Academic Speaking class. Following the conclusion of this report, the results are planned to be used as one of the supplemental materials for teaching and researching the Academic Speaking Course in the English Study Program.
\end{abstract}

Keywords: Online, Resources, Empower, Presentation, Academic Speaking

\section{Introduction}

Classes have been shaped to accommodate so-called digital resources to blend with the demand of the century. Using the world real tools, apps, and resources that are available online are inevitable for learning because today's generation has been exposed and familiar to the usage of digital media technology such as a computer, mobile gadget, and internet connection from a very early time. Prensky [1] suggested this phenomenon as a "digital native generation", meaning that today's children were born into the e-environment and they have access to worldwide information resources. In the area of TESOL, multimedia technology has shaped the face of second language pedagogy and added valuable learning experience [2]. The usage of multimedia resources has drawn learners' engagement and strengthened the teaching process [3]. Digital media resources are considered as an authentic learning resource because it meets the condition of some elements which are suggested as an authentic learning environment [4]. The goal of this study is to find out the following inquiries: what kind of online resource types youth use as their references to help them powerfully present ideas and beliefs on the contemporary issues in society, and how online resources can benefit them in planning and delivering presentations in an academic context. 


\section{Review of Related Literature}

Upon understanding the concept of instructional materials, it is necessary to see types of Instructional materials, which can be applied for classroom sessions. Villena \& Beren [5] proposed instructional materials of the Microcomputer resources type such as any materials made by the use of modern technology to make the teaching and learning session given in a lot of ease e.g., software, hardware, printer, scanner, voice synthesizer, networks. Further Harmer [6] proposes other technology and other learning resources as a part of instructional materials. He defines learning recourses into objects, pictures, and things. Those classifications can be used to manipulate the active involvement of students in the classroom. Examples of an object are realia, cards, pictures, and questioner. The next category is other resources for example course books, display board, dictionary, flip charts, Overhead Projector (OHP), and computerbased presentation technology. Online resources allow ease of information viewing and retrieval. Textbooks and other printed materials are no longer the soles of information sources for the students to seek, not to mention if those printed resources are limited. Students may "search" on the World Wide Web for preprints and reprints of articles, for discussion on specialized topics, or topical compilations of materials for research or presentation. Most Web navigational software systems include search engines that allow the user to locate information or sites by topic area (Example: www.nap.edu/read). There are many different types of online resources, some of them are appropriate for classroom integration. Depending on the type of content that students are looking for. Online resources are getting significant in the percentage of global literature. They refer to information sources in electronic form. The different types of e-resources are, E-books, E-journals, Databases, CDs/DVDs, E-conference proceedings, EReports, E-Maps, E-Pictures/Photographs, E-Manuscripts, E-Theses, E-Newspaper, Internet/Websites, Newsgroups, Subject Gateways, USENET, FAQs, etc. [7].

\section{Research Method}

A descriptive-analysis method is used for this specific research. A descriptive-analysis method of study explains the subject by further examining it. The goal is to classify features, frequencies, trends, associations, and categories [8]. Participants in this study are the fourthsemester student who enrolls in the Academic Speaking Course. Purposive sampling is used in this analysis. Participants in this research would be selected "because of their main participation in the social context and their ability to tell the researcher what they experience, think and feel" [9]. It is well known as purposive sampling [10]. The data for this research shall be obtained from the questionnaire. A questionnaire is designed to be analyzed. The questionnaire is structured to provide information on the types of online resources that students use as their references to help their presentation materials and information on how online resources assist students in planning and delivering the presentation for their Academic Speaking Class. The questionnaire will be distributed through Google form. The questionnaire will be checked by the appointed TESOL expert to respond to the current situation of participants having online classes due to the Covid-19 pandemic. The results of the academic speaking presentation will be uploaded via the student YouTube channel. 


\section{Results and Discussion}

The results of this current study do not merely indicate that the appropriate online resources choice empowers students to complete a particular learning project but also reflect how youths' ideas and beliefs are projected throughout their presentation over some contemporary topics that exist in society such as mind and peacefulness, inspiring people, fashion industry, multicultural living. Related educational resources, as well as online platforms, are useful for raising students 'comprehension, abilities and skills, monitoring their assimilation of information, and contributing to their overall growth and upbringing.

\subsection{Access To and Use of Computer and ICT}

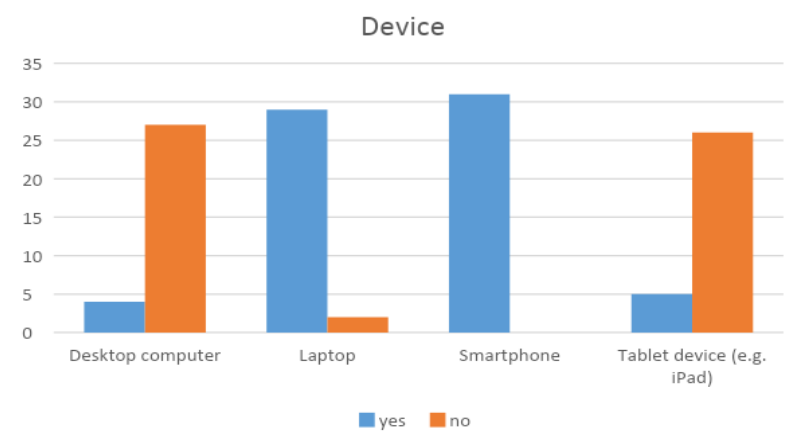

Fig. 1. Chart of student's accessibility toward computer and ICT.

It also revealed that the degree to which online resources that learners use can strengthen their presentation skills for the Academic context by exploring the category of online resources that learners usually use as a reference to their presentation materials. Based on the aforementioned results, it can be inferred that most students have access to smartphones and laptops compared to desktop computers and tablets. Of the 31 participants, all students have full access to smartphones, and 29 students have access to laptops in second place. This proves that smartphones and laptops are devices that are most available to students.

\subsection{Use of ICT's}

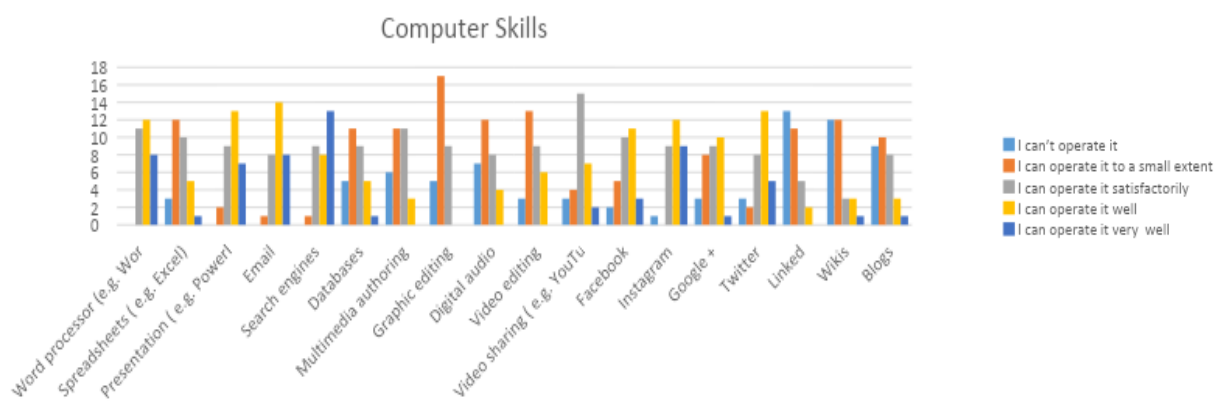

Fig. 2. Chart of students' computer-related skills. 
In addition to ownership of devices, students are also given voting about their proficiency in computer skills such as word processors, spreadsheets, presentations, e-mail, search engines, databases, multimedia authoring, graphic editing, digital audio, video editing, video sharing, Facebook, Instagram, Google+, Twitter, Linked, wikis, and blogs. Among the 18 computer skills, students are given 5 choices, namely, I can operate it, I can operate it to a small extent, I can operate it satisfactorily, I can operate it well, and I can operate it very well. From the answers that have been collected, it can be seen that Linked occupies the top position as a computer skill which is very difficult to operate for students by getting 13 votes of them choosing, I can't operate it. The second option, in which students can operate it to a small extent, is occupied by graphic editing skills with a total vote of 17 . The third, in which the students can operate it satisfactorily is a skill in video sharing with the highest total score of 15 votes. And the next choice of answer, namely I can operate it well is occupied by e-mail with the most total votes of 14 votes. The last computer skill that has the highest number of votes where students can operate it very well is a skill in operating search engines with several votes of 13 .

\subsection{Online Sources Platform Preference}

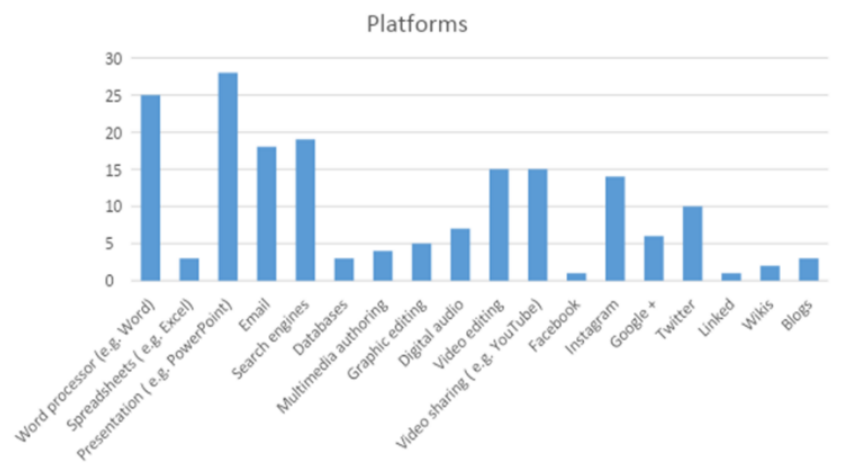

Fig. 3. Chart of online source platform preference.

As far as online platform preferences are concerned, the results show that presentations, word processors, search engines, email, video editing, video sharing, Instagram, and Twitter are the top 8 online source platforms chosen by students as their preferred media in the preparation of content materials for their Academic Speaking presentation content. Of the 8 online source platforms, the use of presentations such as PowerPoint presentation ranks at the top, and Word Processors such as Microsoft Word rank second. The remaining channels such as digital audio, Google+, graphic editing, interactive authoring, databases, spreadsheets, blogs, wikis, links, and Facebook are considered to be the least favored online resource for students. 


\subsection{Online Resources Platform Recommendation}

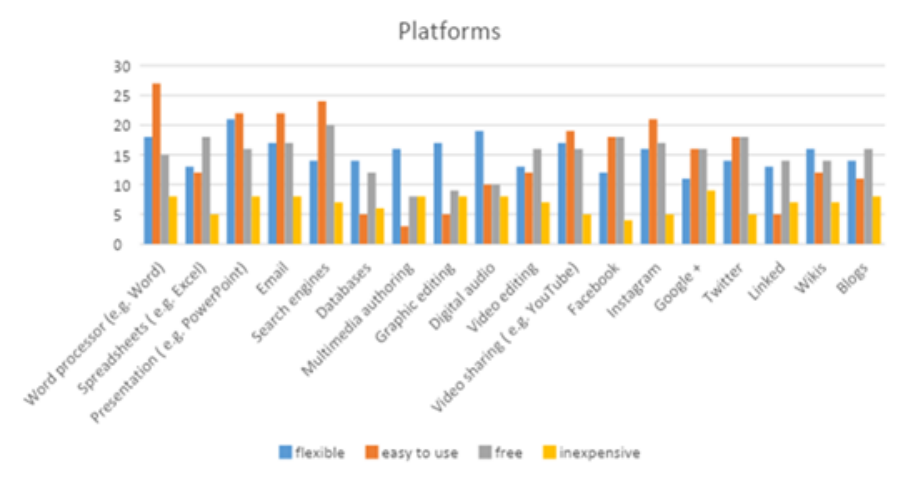

Fig. 4. Chart of online resource platform recommendation.

Students also voted for the online source platform that they would suggest to help the preparation and creation of content material for Academic Speaking Presentation for its versatility, ease, and free or inexpensive. Among the 18 platforms, the presentation ranks number one as the most versatile platform for students to prepare materials for their subjects. In comparison to usability, voting indicates that the word processor is the easiest online source tool. In comparison to the first and second dimensions, search engines have taken the first spot as the freest online source site. And the last one is the cheapest site occupied by Google+. However, in general, an online platform that can cover all four aspects; scalable, easy-to-use, open, and low-cost, with a high number of votes is presented. Presentation, in general, has the largest number of votes on all four parameters compared to 17 other channels with a total of 21 versatile votes, 22 easy-to-use, 26 free, and 8 low-cost votes.

\subsection{Students' Perception on the Use of Online Resources}

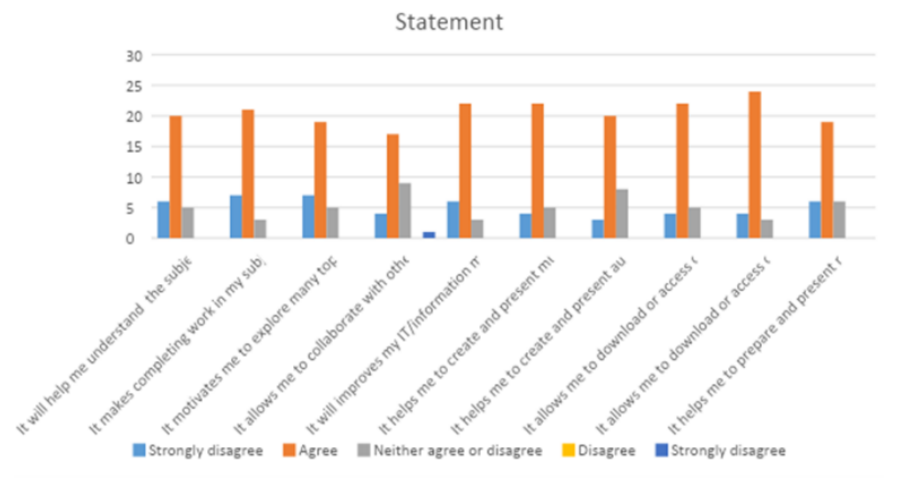

Fig. 5. Chart of students' perception of the use of online resources.

The last inquiry is about students' perception of the use of online resources in planning their presentation for their Academic Speaking course. On average, according to the above results, all students accept that online resources are useful in 10 dimensions. Second, the use of 
online resources is advantageous for downloading or accessing online texts or databases to support their preparation of material content. In addition, online resources also enable them to download or access online audio/video, build and present multimedia shows, and develop their IT/information management skills in general. The fourth factor is that it makes doing work in student subjects more convenient. The next factor is that it helps students build and present audio/video shows and helps them to appreciate the content more thoroughly. Besides, online tools allow them to explore a variety of subjects that they may not have learned before. Apart from that, it also allows them to plan and deliver their academic presentation more confidently. The last point that students agree on about the use of online resources is that they should make it easier for them to work with others, both on and off-campus.

Considerably, the internet-based available resources help young people in portraying the existing issues within society. They manage to present some contemporary and current topics with very sufficient data and evidence taken from online resources in the form of infographics, news articles, charts and graphs, pictorials and illustrations, journal articles, visual aids, and so on to support their position and contentions. They can extend and elaborate their repertoire to any particular arguments. An instance of this, one of the topics presented is the Fast Fashion Industry. Fast Fashion Industry is a term used by fashion retailers to characterize low-cost designs that move quickly from the catwalk to stores to meet emerging styles. As a result of this trend, the practice of introducing new fashion lines on a seasonal basis has also been challenged (Example: https://www.thegoodtrade.com). With the help of online resources, these young people are able to display powerful supporting data for their arguments. They raise public awareness by providing information from online resources on how the Fast Fashion Industry has had an impact on global society, namely how it has contributed to the existence of child labor in Bangladesh for example, in the pursuit of cheap employees by avaricious of fashion manufacturing companies. They also declare a few trustworthy data on how much the Fast Fashion Industry is also damaging the planet by pollution and waste materials. Thus, they also provide the counter-part action against this by upholding a more sustainable and lowimpact fashion.

As the presentation also revealed, the Multicultural Society is another topic that is well developed through an assistant to a large number of online resources. This issue is a genuine issue to be dealt with in the presentation. Students prepare materials on what they discover on the Internet in some factual cases of the Multicultural Society, such as potential conflicts, negotiation strategies at the time of the dispute, and celebration of diversity. The result of exploring supporting data for presentation via online resources has significantly increased students' confidence in delivering their values and convictions. Their presentation is more attractive and thought-provoking. In support of Awolaju's opinion [11] on Instructional Material, Awolaju proclaimed that the teaching material could be explained as a device by which knowledge, skills, attitudes, ideas, beliefs, and values were conveyed to the learner by the teacher to promote the learning process.

The implication of the finding is in line with Castells' informational society [12]. Castells describes the modern social environment as the Information Age, in which human societies perform their actions according to a different technological model, and argues that this landscape was brought on by the information and communication technology (ICT) revolution in the second half of the twentieth century. He also says that all technologies, from ICT to genetic modification, are now inextricably related to ICT. It means the information is handled in some way by ICT. According to the results, students are the digital native generation living in the Information Age, thanks to an array of online information resources on which they can rely. The students deliver a powerful presentation as a result of their thorough preparation for 
the issues/topics raised during their academic speaking class. The accessible information sources include a range of supporting evidence to be discussed, so their presentation on a single topic is justified. According to Castells [12], the term "informational" refers to a specific type of social organization in which information gathering, processing, and distribution have become the primary sources of productivity and control as a result of new technological conditions that have emerged in the modern era.

\section{Conclusion}

In conclusion, a variety of online resources are available, some of which are ideal for classroom integration. Depending on the type of content the students are looking for. Online networks are becoming increasingly prominent in the percentage of global literature. The results of this current study demonstrate that an appropriate choice of online resources empowers students to complete a specific learning project. Related educational resources, as well as online platforms, are useful for increasing students' awareness, skills and abilities, monitoring their assimilation of information, and contributing to their overall growth and upbringing. Finally, it is also revealed that the degree to which online resources that learners use can enhance their presentation skills for the Academic context by exploring the category of online resources that learners usually use as a reference to their presentation materials.

\section{References}

[1] M. Prensky, "Digital natives, digital immigrants part 2: Do they really think differently?," Horiz., 2001.

[2] M. T. Romano, Empowering teachers with technology: Making it happen. Scarecrow Press, 2003.

[3] B. Tomlinson, Developing materials for language teaching. A\&C Black, 2003.

[4] H. Chen, "EDGT 940 on campus-delivery Spring 2012," Univ. Wollongong, 2012.

[5] Villena and Beren, "Instructional materials/technology," 2015.

[6] J. Harmer, "The practice of English language teaching. Harlow," English: Pearson Longman, 2007.

[7] A. Y. Kenchakkanavar, "Types of e-resources and its utilities in library," Int. J. Inf. Sources Serv., vol. 1, no. 2, pp. 97-104, 2014.

[8] S. Loeb, S. Dynarski, D. McFarland, P. Morris, S. Reardon, and S. Reber, "Descriptive Analysis in Education: A Guide for Researchers. NCEE 2017-4023.," Natl. Cent. Educ. Eval. Reg. Assist., 2017.

[9] L. Kervin, W. Vialle, J. Herrington, and T. Okely, "Research for Educators. Thomson." Social Science Press, South Melbourne, 2006.

[10] K. Cliff, EDGZ 921 on campus-delivery Spring 2012. The University of Wollongong, 2012.

[11] B. A. Awolaju, "Instructional materials as correlates of students' academic performance in Biology in senior secondary schools in Osun State," Int. J. Inf. Educ. Technol., vol. 6, no. 9, pp. 705-709, 2016.

[12] M. Castells, The information age: economy, society and culture. Blackwell, 1991. 